\section{Sigmoid Perforation: A Rare Complication of a Migrated Biliary Endoprosthesis}

We report here a case of perforation of the sigmoid by a migrated biliary endoprosthesis. The 77-year-old woman was admitted with symptoms secondary to reumathoid arthritis. A straight biliary endoprosthesis had been placed six months previously because of unremovable bile duct stones. She had had no symptoms from the biliary stones or stent during these six months. Two weeks after admission, she became febrile, with mild tenderness mainly in the lower left quadrant of the abdomen, leukocytosis, and disturbed liver function tests. On a plain radiograph, the endoprosthesis was found in the left lower abdomen (Figure 1). At endoscopic retrograde cholangiopancreatography, a nasobiliary drain was placed and the liver tests improved, but the fever persisted. Peritonitis was diagnosed, and at laparotomy pus was present in the abdomen. The endoprosthesis had perforated the sigmoid colon at the site of a diverticulum.

A colon perforation by a migrated biliary stent is a very rare event $(1-5)$. Two factors may play a role in the occurrence of such a perforation. Firstly, the wall of a colon diverticulum is thinner than the colon wall proper. Secondly, an endoprosthesis that lodges in a diverticulum can only move forward when it is bent by the forward-moving contents of the colon. The stiffer the endoprosthesis, the more difficult it will be for it to bend. The opposite end of the endoprosthesis may also get stuck in the colon wall, and a colon contraction may then result in a perforation. The stiffness of the endoprosthesis depends on the thickness of the wall and the properties of the material. Most plastic materials tend to become stiffer with time in the body. To prevent this kind of complication, pliable endoprostheses with a thin wall should be used. 
Earlier endoscopic removal of the stent in our case could probably have prevented the perforation. Most of us. however, would prefer to await spontaneous evacuation in a patient without symptoms. A more aggressive approach should probably be followed in patients with known diverticulosis, if the endoprosthesis remains in the same position for a tew days. Colonoscopic removal also involves risks. Colon preparation by enema is probably less risky than total body livage. The endoprosthesis should first be moved carefully out of the diverticulum, and should only be pulled out when it is lying free in the lumen.

R. J. II. Schadsma', P. Spoelstra, J. Pakan', K. Huibregrse

Dept of Surgery. Medical Center, Leeuwarden. The Netherlands

Dept of Internal Medicine. Medical Center. Leeuwarden. The

Netherlands

Dept. of (iastroenterology and Hepatology, Academic Medical

Center. Amsterdam. The Netherlands

\section{References}

I. Mueller PR, Ferruci JR Jr. Teplick SK, et al. Biliary stent endoprosthesis: analysis of complications in 113 patients. Radiology 1985: 156: 637-9.

2. Gould J. Train JS. Dan SJ. et al. Duodenal perforation as a delayed complication of placement of a biliary endoprosthesis. Radiology 1988: 167: 467-9.

3. Miskow iak J. Mygind T, Bader H. et al. Biliary endoprosthesis secured by a subcutaneous button to prevent disclocation. Am I Roentgenol 1982; 139: 1019-20.

4. Johanson Jf. Schmalz MJ. Geenen JE. Incidence and risk factors for biliary and pancreatic stent migration. (iastrointest Endose 1992: $38: 341-6$.

5. Ruffolo TA. Lehman GA, Sherman S. el al. Biliary stent migration with colonic diverticular impaction. Gastrointest Endose 1942: 38: 81-3.

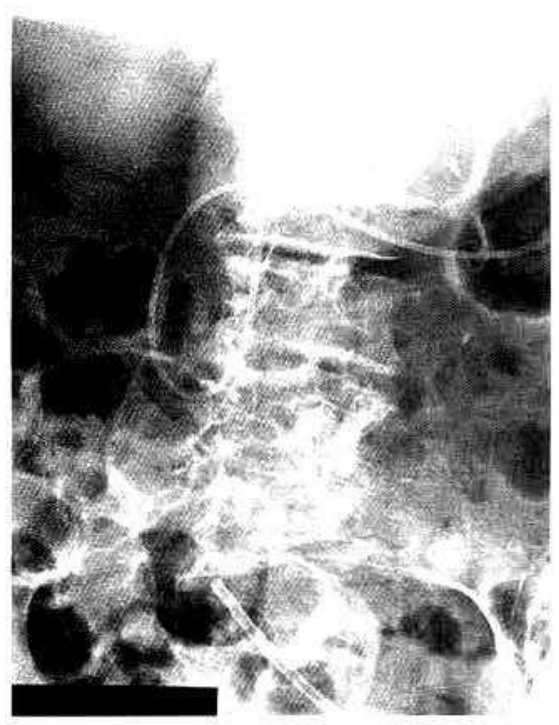

Figure 1: The mgrated stent in the lett pelvis A nasobihary drain is in place

\section{Comesponding duthor}

K. Ifuibregtse. M. D.

Dept. of Ciastroenterology and Hepatology

Academic Medical center

University of Amsterdam

Meibergdreef 9

1105 A7. Amsterdam

The Netherlands

Fax: $-31-20-6917033$ 